\title{
PRODUTIVIDADE DO EUCALIPTO, ATRIBUTOS FÍSICOS DO SOLO E FRAÇÕES DA MATÉRIA ORGÂNICA INFLUENCIADAS PELA INTENSIDADE DE TRÁFEGO E RESÍDUOS DE COLHEITA
}

\author{
Guilherme Luiz de Jesus $^{(1)}$, Ivo Ribeiro Silva ${ }^{(2)}$, Luís Fernando Januário Almeida ${ }^{(3)^{*}}$, Mateus \\ Alves dos Santos ${ }^{(4)}$, Fernando Palha Leite ${ }^{(1)}$ e Júlio César Lima Neves ${ }^{(2)}$ \\ (1) Celulose Nipo-Brasileira S/A, Belo Oriente, Minas Gerais, Brasil. \\ (2) Universidade Federal de Viçosa, Departamento de Solos, Viçosa, Minas Gerais, Brasil. \\ (3) Universidade Federal de Viçosa, Departamento de Solos, Programa de Pós-graduação em Solos e Nutrição de Plantas, Viçosa, \\ Minas Gerais, Brasil. \\ (4) Universidade Federal de Viçosa, Departamento de Fitotecnia, Programa de Pós-graduação em Fitotecnia, Viçosa, Minas \\ Gerais, Brasil. \\ * Autor correspondente. \\ E-mail: luisalmeidaufv@gmail.com
}

\begin{abstract}
RESUMO
O número de passadas das máquinas, os tipos de rodados e a alta umidade do solo durante as operações de colheita agravam o processo de compactação, devendo-se conhecer esses impactos e quais alternativas para reduzí-los. $O$ objetivo deste estudo foi avaliar o impacto de diferentes frequências de tráfego do forwarder e o efeito de condições distintas de resíduos da colheita do eucalipto ao fim da rotação subsequente na produtividade, nos atributos físicos do solo e nos teores de matéria orgânica de um Latossolo Vermelho (LV), localizado em São João Evangelista, MG, e um Latossolo Amarelo (LA), localizado em Belo Oriente, MG. Os tratamentos consistiram de um esquema fatorial $2 \times 3$, sendo: duas ou oito passadas na entrelinha sobre resíduo da colheita sem casca; com casca; e sem resíduo. A perda de produtividade dos plantios pela compactação do solo proveniente das passadas do forwarder é atenuada com a permanência dos resíduos da colheita especialmente com a manutenção da casca na área. A remoção de resíduo, particularmente quando há remoção da casca, leva à redução dos teores de $\mathrm{C}$ orgânico total e de frações mais lábeis de $\mathrm{C}$ e $\mathrm{N}$ do solo. $\mathrm{O}$ tráfego do forwarder na colheita do eucalipto da rotação anterior sobre solo sem resíduos promove perdas na qualidade física do solo, com aumento da densidade do solo e resistência à penetração, e redução
\end{abstract}




\author{
na porosidade e condutividade hidráulica do solo. Esses efeitos negativos perduraram \\ até o final da rotação seguinte.
}

Palavras-chave: compactação do solo, resistência à penetração, carbono lábil, forwarder.

\begin{abstract}
EUCALYPTUS PRODUCTIVITY, SOIL PHYSICAL PROPERTIES AND ORGANIC MATTER FRACTIONS INFLUENCED BY TRAFFIC INTENSITY AND HARVEST RESIDUES
\end{abstract}

\begin{abstract}
The number of machine passes, types of wheels, and high soil moisture during harvest operations affect the soil compaction process. The impacts of these factors and alternatives to reduce them must be better understood. This study evaluated the impact of different traffic intensities of a loaded forwarder and the effect of different management conditions of eucalyptus harvest residues on productivity, soil physical properties, and organic matter at the end of the subsequent rotation in two Oxisols in the State of Minas Gerais, Brazil. The treatments consisted of a $2 \times 3$ factorial arrangement: two or eight machine passes between rows over crop residue without bark, crop residue with bark, or an area without residue. Eucalypt wood productivity losses due to soil compaction caused by forwarder traffic is mitigated by the presence of harvest residues, especially when bark is maintained in the area. Residue removal, and especially bark removal, leads to reduction in total organic $C$ content and the more labile $C$ and $N$ fractions of the soil. Forwarder traffic in the harvest of the previous rotation of eucalyptus on soil without residues leads to losses in soil physical quality, with increased bulk density and resistance to penetration, and reduction in porosity and hydraulic conductivity. These negative effects were observed up to the end of the following rotation.
\end{abstract}

Keywords: soil compaction, penetration resistance, labile carbon, forwarder.

\section{INTRODUÇÃO}

Uma intensa mecanização do setor florestal a partir da década de 1990 tem ocorrido para atender a demanda do mercado a custos competitivos diante da crescente dificuldade de mão de obra. Por se tratar em sua maioria de máquinas de grande porte, principalmente na colheita de madeira, têm-se como consequência direta das operações florestais alterações em diversos atributos físicos e mecânicos do solo (Silva et al., 2007).

A compactação do solo reduz o espaço poroso e a infiltração da água (Reichert et al., 2007). O aumento nos níveis de compactação do solo pode por sua vez interferir negativamente na produtividade (Dias Júnior, 1999; Cavichiolo et al., 2005; Reichert et al., 2009), em razão do baixo desenvolvimento do sistema radicular (Marchão et al., 2007) e do impedimento mecânico, que resulta em menor volume de solo explorado e menor absorção de água e nutrientes. A compactação do solo tem se destacado em nível mundial como sendo um dos fatores limitantes da qualidade física do solo, prejudicando alcançar maiores índices de produtividade (Alakukku e Elomen, 1994); é também apontada como um dos principais fatores da degradação de solos agrícolas (Canillas e Salokhe, 2002).

De acordo com os atributos edáficos como a textura e a mineralogia do solo, os impactos relacionados ao tráfego de máquinas podem potencializar o processo de compactação do solo. Da mesma forma, o número de passadas das máquinas, os tipos de rodados utilizados e o alto conteúdo de água no solo durante as operações agravam o processo de compactação (Seixas, 2000; Lopes et al., 2006, 2011).

O módulo de colheita de madeira utilizado condiciona o percentual da área que será atingido pelo deslocamento das máquinas (Seixas e Souza, 2007). Assim, a utilização de feller-buncher e skidder na colheita florestal resulta que, pelo menos uma vez, praticamente, toda área será submetida ao tráfego e distúrbio do solo pelo arraste das árvores até a borda do talhão. Já no módulo harvester - forwarder, o tráfego ficará concentrado nos ramais de extração de madeira, com a área trafegada dependendo da distância entre esses (Fenner, 2002).

O forwarder é uma máquina projetada para o baldeio da madeira já cortada, com ou sem casca, de dentro da floresta para a periferia dos talhões, de modo a evitar o tráfego dos veículos de transporte dentro da floresta. No entanto, segundo Seixas e Souza (2007), $80 \%$ do incremento da compactação de um solo ocorreram após as cinco primeiras passadas de um forwarder. Estudando o efeito do número de passadas de um forwarder nas regiões de Belo Oriente e São João Evangelista, Silva et al. (2010) verificaram que o maior número de passadas causou maior compactação do solo, sendo essa minimizada nas condições em que foram mantidos os resíduos, a galhada mais casca e galhada, no ato da colheita. Os efeitos na produtividade do eucalipto e na MOS, no entanto, não foram avaliados. Nesse sentido, é 
necessário entender e desenvolver estratégias de manejo que visem reduzir o efeito da compactação na produtividade do eucalipto e atuar sobre as causas desse problema.

O objetivo deste estudo foi avaliar o impacto de diferentes intensidades de tráfego do forwarder e o efeito de condições distintas de deposição de resíduos da colheita do eucalipto ao fim da rotação na produtividade, nos atributos físicos do solo e nos teores de matéria orgânica de um Latossolo Vermelho oxídico e um Latossolo Amarelo caulinítico ao final da rotação seguinte.

\section{MATERIAL E MÉTODOS}

\section{Descrição da área de estudo}

Este estudo foi realizado em áreas da Celulose Nipo-Brasileira S.A. (Cenibra), num Latossolo Vermelho (LV), textura muito argilosa $\left(750 \mathrm{~g} \mathrm{~kg}^{-1} \mathrm{de}\right.$ argila), oxídico, localizado no município de São João Evangelista, MG, a $18^{\circ} 34^{\prime} 12^{\prime \prime} \mathrm{S}$ e $42^{\circ} 52^{\prime} 53^{\prime}$ W, com altitude de $860 \mathrm{~m}$; e num Latossolo Amarelo (LA), textura argilosa (590 $\mathrm{g} \mathrm{kg}^{-1}$ de argila), caulinítico, no município de Belo Oriente, $\mathrm{MG}$, a $19^{\circ} 18^{\prime} 23^{\prime}$ 'S e $42^{\circ} 25^{\prime} 31^{\prime}$ W, com altitude de $300 \mathrm{~m}$.

A colheita florestal foi realizada em janeiro de 2005 com o uso de motosserra, e a extração da madeira foi feita com forwarder (marca Valmet, modelo $636 \mathrm{~S}$ ), com massa de $11,9 \mathrm{Mg}$, carregado com $9 \mathrm{~m}^{3}$ de madeira (densidade básica de $480 \mathrm{~kg} \mathrm{~m}^{-3}$ ).

Os tratamentos consistiram de um esquema fatorial $2 \times 3$, sendo: tráfego do forwarder duas ou oito vezes sobre resíduo da colheita do eucalipto sem casca (SC); resíduo da colheita do eucalipto com casca (CC); e solo sem resíduo (SR). Para comparar o efeito das passadas do forwarder nos atributos físicos do solo e nos teores de matéria orgânica, amostras na entrelinha de tráfego foram coletadas e consideradas como zero passadas. As parcelas eram de $36 \mathrm{~m}$ de comprimento e $4 \mathrm{~m}$ de largura, com $144 \mathrm{~m}^{2}$ de área, sendo a linha de 12 plantas a parcela total e 10 plantas úteis. O espaçamento entre as árvores foi de $3 \times 3,33 \mathrm{~m}$. O delineamento experimental foi em blocos casualizados, com duas repetições.

Após a colheita, realizou-se o plantio na entrelinha no mês de maio de 2005 em Belo Oriente (BO), com o clone 1213, híbrido de Eucalyptus urophylla $\times$ E. grandis, e em São João Evangelista (SJE), instalado em agosto de 2005 com o clone 911, híbrido de $E$. urophylla $\times$ E. grandis. A adubação de plantio, a de cobertura e a fonte de $\mathrm{Ca}$ e $\mathrm{Mg}$ foram as mesmas e aplicadas nas mesmas épocas para todos os tratamentos.

\section{Coleta e análises de amostras de solo}

Amostras de solo foram coletadas quando as árvores estavam com 5,88 anos de idade em BO e 5,61 anos de idade em SJE.

Para avaliar a qualidade física do solo, em cada parcela de cada bloco foram coletadas amostras com anéis metálicos de $100 \mathrm{~cm}^{3}$, sendo seis amostras (três na camada de 0,025-0,075 m e três na camada de 0,125-0,175 m de profundidade do solo; equivalente ao centro das camadas de 0,00-0,10 e 0,10-0,20 m) em cada condição de tráfego do forwarder (zero, duas ou oito passadas). Nas amostras, determinaram-se, em laboratório, a condutividade hidráulica em meio saturado $\left(\mathrm{K}_{0}\right)$ com permeâmetros de carga constante (Ferreira, 1999); microporosidade após tensão de $6 \mathrm{kPa}$; densidade do solo (Ds) pelo método do anel volumétrico; densidade das partículas $(\mathrm{Dp})$ pelo método do balão volumétrico; porosidade total (PT) pela equação $\mathrm{PT}=1$ - (Ds/Dp); e macroporosidade dada pela diferença entre PT e microporosidade (Embrapa, 1997).

A resistência à penetração $(\mathrm{RP})$ foi definida até a profundidade de $60 \mathrm{~cm}$ de solo, por meio do uso de um penetrômetro de impacto modelo IAA/Planalsucar-Stolf (Stolf et al., 1983). Dentro de cada tratamento, foram realizadas cinco avaliações em cada condição de tráfego do forwarder (zero, duas ou oito passadas). Amostras de solo também foram coletadas, acondicionadas em recipientes de alumínio, hermeticamente fechados e levados ao laboratório para determinar a umidade do solo nas camadas de $0,00-0,10 ; 0,10-0,20 ; 0,20-0,40$; e 0,40-0,60 $\mathrm{m}$ de profundidade.

Para as análises químicas do solo, foram coletadas amostras na camada de 0,00-0,20 m, sendo cinco amostras simples para formar uma amostra composta. Para cada parcela de disposição de resíduo (CC, SC e SR), coletou-se uma amostra composta em cada condição de tráfego do forwarder (zero, duas ou oito passadas). As amostras foram secas ao ar, destorroadas, passadas em peneiras de $2 \mathrm{~mm}$ de malha, homogeneizadas e, posteriormente, submetidas às análises químicas (Quadro 1). Foram determinados: $\mathrm{pH}$ em água; $\mathrm{Al}, \mathrm{Ca}$ e $\mathrm{Mg}$ trocáveis, extraídos com KCl $1 \mathrm{~mol} \mathrm{~L}^{-1}$; P e K extraídos pelo Mehlich-1, de acordo com método descrito por Defelipo e Ribeiro (1997). Nos extratos, os teores de $\mathrm{P}$ foram determinados por colorimetria (Braga e Defelipo, 1974); os de K, por fotometria de chama; e os de $\mathrm{Ca}, \mathrm{Mg}$ e Al, por espectrofotometria de absorção atômica (AOAC, 1975). Os teores de Fe, Mn, Zn, e $\mathrm{Cu}$ foram determinados por espectrofotometria de absorção atômica, após extração com Mehlich-1. O P remanescente foi determinado de acordo com Alvarez V et al. (2000). A caracterização granulométrica foi realizada segundo Ruiz (2005). Para determinar a classe mineralógica dos solos, realizou-se ataque sulfúrico conforme Embrapa (1997, 2013) (Quadro 2). 
Quadro 1. Características químicas do solo após zero, duas ou oito passadas do forwarder sobre resíduo da colheita do eucalipto sem casca (SC); resíduo com casca (CC); e solo sem resíduo (SR) de um Latossolo Vermelho em São João Evangelista, MG, aos 5,61 anos de idade do plantio e de um Latossolo Amarelo em Belo Oriente, MG, aos 5,88 anos de idade do plantio

\begin{tabular}{|c|c|c|c|c|c|c|c|c|c|c|c|c|c|c|c|}
\hline $\mathrm{N}^{\circ}$ de passada & Resíduo & $\mathrm{pH}\left(\mathrm{H}_{2} \mathrm{O}\right)^{(1)}$ & $\mathbf{P}^{(2)}$ & $\mathbf{K}$ & $\mathrm{Na}$ & $\mathbf{C a}^{2+(3)}$ & $\mathrm{Mg}^{2+(3)}$ & $\mathrm{Al}^{3+(3)}$ & SB & $\mathbf{t}$ & $\mathbf{Z n}^{(3)}$ & $\mathrm{Cu}^{(3)}$ & $\mathrm{Fe}^{(3)}$ & $\mathbf{M n}^{(3)}$ & Prem $^{(4)}$ \\
\hline & & & \multicolumn{3}{|c|}{$\mathrm{mg} \mathrm{dm}^{-3}$} & \multicolumn{5}{|c|}{$\mathrm{cmol}_{\mathrm{c}} \mathrm{dm}^{-3}$} & \multicolumn{5}{|c|}{$\mathrm{mg} \mathrm{dm} \mathrm{m}^{-3}$} \\
\hline & & \multicolumn{14}{|c|}{ Latossolo Vermelho - São João Evangelista $(0-20 \mathrm{~cm})$} \\
\hline 0 & SR & 4,42 & 3,70 & 26,54 & 2,87 & 0,37 & 0,10 & 1,65 & 0,55 & 2,21 & 0,26 & 0,28 & 103,02 & 3,08 & 20,23 \\
\hline 0 & $\mathrm{SC}$ & 4,38 & 2,57 & 29,81 & 2,95 & 0,26 & 0,10 & 1,70 & 0,46 & 2,16 & 1,52 & 1,12 & 158,92 & 2,93 & 20,85 \\
\hline 0 & $\mathrm{CC}$ & 4,65 & 1,81 & 29,12 & 3,58 & 0,95 & 0,19 & 1,34 & 1,24 & 2,58 & 0,73 & 0,41 & 144,36 & 4,70 & 21,58 \\
\hline 2 & SR & 4,37 & 2,69 & 28,50 & 3,29 & 0,16 & 0,08 & 1,79 & 0,33 & 2,13 & 0,72 & 0,52 & 92,86 & 2,43 & 20,57 \\
\hline 2 & $\mathrm{SC}$ & 4,49 & 2,15 & 30,50 & 4,00 & 0,56 & 0,16 & 1,39 & 0,81 & 2,20 & 0,35 & 0,28 & 133,69 & 4,66 & 21,54 \\
\hline 2 & $\mathrm{CC}$ & 4,37 & 1,27 & 33,25 & 3,06 & 0,41 & 0,11 & 1,83 & 0,62 & 2,44 & 0,57 & 0,22 & 86,89 & 3,01 & 19,10 \\
\hline 8 & SR & 4,43 & 2,16 & 28,13 & 3,18 & 0,26 & 0,10 & 1,59 & 0,44 & 2,04 & 0,53 & 0,38 & 85,25 & 3,77 & 18,47 \\
\hline 8 & $\mathrm{SC}$ & 4,43 & 3,33 & 33,37 & 3,67 & 0,37 & 0,12 & 1,61 & 0,60 & 2,21 & 0,78 & 0,45 & 266,31 & 4,48 & 19,18 \\
\hline 8 & $\mathrm{CC}$ & & 4,18 & 37,29 & 3,18 & 0,70 & 0,14 & 1,35 & 0,95 & 2,30 & 1,20 & 0,61 & 179,74 & 6,08 & 21,87 \\
\hline \multicolumn{2}{|l|}{ Média $(0-20$ cm) } & & 2,65 & 30,72 & 3,31 & 0,45 & 0,12 & 1,58 & 0,67 & 2,25 & 0,74 & 0,48 & 139,00 & 3,90 & 20,38 \\
\hline & & \multicolumn{14}{|c|}{ Latossolo Amarelo - Belo Oriente $(0-20 \mathrm{~cm})$} \\
\hline 0 & $\mathrm{SR}$ & 4,47 & 1,06 & 22,75 & 2,82 & 0,03 & 0,04 & 2,00 & 0,14 & 2,15 & 0,76 & 0,27 & 57,43 & 1,62 & 6,53 \\
\hline 0 & $\mathrm{SC}$ & 4,50 & 1,30 & 26,88 & 3,29 & 0,04 & 0,04 & 2,09 & 0,17 & 2,26 & 0,51 & 0,27 & 57,62 & 1,76 & 6,78 \\
\hline 0 & $\mathrm{CC}$ & 4,62 & 4,24 & 25,00 & 3,17 & 0,14 & 0,07 & 1,81 & 0,28 & 2,09 & 0,70 & 0,17 & 52,19 & 1,95 & 6,50 \\
\hline 2 & SR & 4,68 & 0,53 & 21,50 & 3,06 & 0,03 & 0,04 & 1,56 & 0,13 & 1,70 & 0,81 & 0,36 & 46,32 & 1,33 & 7,74 \\
\hline 2 & $\mathrm{SC}$ & 4,51 & 1,52 & 25,25 & 3,29 & 0,03 & 0,05 & 2,04 & 0,16 & 2,20 & 0,64 & 0,27 & 54,74 & 1,63 & 7,00 \\
\hline 2 & $\mathrm{CC}$ & 4,64 & 1,13 & 25,25 & 3,76 & 0,05 & 0,05 & 1,89 & 0,18 & 2,08 & 0,65 & 0,23 & 54,36 & 1,97 & 6,59 \\
\hline 8 & SR & 4,53 & 0,99 & 23,75 & 2,59 & 0,02 & 0,04 & 2,10 & 0,14 & 2,23 & 0,85 & 0,42 & 54,48 & 1,66 & 5,57 \\
\hline 8 & $\mathrm{SC}$ & 4,54 & 2,75 & 30,50 & 4,00 & 0,05 & 0,06 & 2,34 & 0,20 & 2,54 & 0,73 & 0,21 & 117,94 & 1,77 & 4,88 \\
\hline 8 & $\mathrm{CC}$ & 4,54 & 1,60 & 24,75 & 2,82 & 0,06 & 0,07 & 2,08 & 0,21 & 2,29 & 0,47 & 0,16 & 50,98 & 2,80 & 5,97 \\
\hline Média $(0-20 \mathrm{~cm})$ & & 4,56 & 1,68 & 25,07 & 3,20 & 0,05 & 0,05 & 1,99 & 0,18 & 2,17 & 0,68 & 0,26 & 60,67 & 1,83 & 6,40 \\
\hline
\end{tabular}

(1) Defelipo e Ribeiro (1997); ${ }^{(2)}$ Braga e Defelipo (1974); ${ }^{(3)}$ AOAC (1975); e ${ }^{(4)}$ Alvarez V et al. (2000).

Quadro 2. Características mineralógicas de um Latossolo Vermelho (LV), em São João Evangelista, MG, e um Latossolo Amarelo (LA), em Belo Oriente, MG

\begin{tabular}{|c|c|c|c|c|c|c|}
\hline Solo & $\mathrm{SiO}_{2}$ & $\mathrm{Al}_{2} \mathrm{O}_{3}$ & $\mathrm{Fe}_{2} \mathrm{O}_{3}$ & Ki & $\mathbf{K r}$ & Classe mineralógica $^{(1)}$ \\
\hline \multirow[b]{2}{*}{ LV } & \multicolumn{3}{|c|}{$\mathrm{g} \mathrm{kg}^{-1}$} & \multirow[b]{2}{*}{0,85} & \multirow[b]{2}{*}{0,71} & \multirow[b]{2}{*}{ Oxídico-caulinítico } \\
\hline & 123 & 245 & 80 & & & \\
\hline LA & 245 & 252 & 77 & 1,65 & 1,38 & Caulinítico \\
\hline
\end{tabular}

Ki: relação molecular $\mathrm{SiO}_{2} / \mathrm{Al}_{2} \mathrm{O}_{3}$; e $\mathrm{Kr}$ : relação molecular $\mathrm{SiO}_{2} /\left(\mathrm{Al}_{2} \mathrm{O}_{3}+\mathrm{Fe}_{2} \mathrm{O}_{3}\right){ }^{(1)}$ Embrapa $(1997,2013)$.

O carbono orgânico total (COT) do solo foi quantificado segundo Yeomans e Bremner (1988), sendo a dosagem feita pela titulação do dicromato remanescente da oxidação.

O carbono lábil (CL) foi quantificado por meio da oxidação com $\mathrm{KMnO}_{4} 33 \mathrm{mmol} \mathrm{L}^{-1}$ como proposto por Blair et al. (1995) e modificado por Shang e Tiessen (1997). O nitrogênio lábil (NL) foi determinado segundo Sahrawat (1982), utilizando-se $10 \mathrm{~mL}$ do extrato do CL e $25 \mathrm{~mL}$ de $\mathrm{NaOH} 10 \mathrm{~mol} \mathrm{~L}^{-1}$ e dosado por titulação ( $\mathrm{HCl} 0,01 \mathrm{~mol} \mathrm{~L}^{-1}$ ) após destilação Kjeldahl. O nitrogênio total (NT) foi quantificado nas amostras de solo sendo dosado por titulação após destilação Kjeldahl (Bremner e Mulvaney, 1982).

\section{Medição, coleta e análise do material vegetal}

O diâmetro do tronco à altura de $1,3 \mathrm{~m}$ (dap) e a altura de todas as árvores da área útil da parcela foram medidos aos 2,88 e 5,88 anos em $\mathrm{BO}$ e aos 2,61 e 5,61 anos em SJE, determinando, assim, o incremento médio anual (IMA, $\mathrm{m}^{3} \mathrm{ha}^{-1} \mathrm{ano}^{-1}$ ) com base nas equações ajustadas: $\hat{\mathbf{y}}=0,004761+0,000033127$ (dap ${ }^{2}$ Altura), no caso de SJE; e $\hat{\mathbf{y}}=0,014562+0,0000323$ (dap ${ }^{2}$ Altura), no caso de BO (Cenibra, dados não publicados).

Amostras de serapilheira foram coletadas em cada parcela. Para tanto, foram tomadas quatro amostras simples (duas nas linhas e duas nas entrelinhas de plantio) para compor uma amostra representativa da parcela, utilizando um gabarito de $0,5 \times 0,5 \mathrm{~m}$ na última idade avaliada. Após determinar a massa de 
matéria fresca, as amostras foram secas em estufa de circulação forçada de ar a $65^{\circ} \mathrm{C}$ por $72 \mathrm{~h}$, para determinar a massa de matéria seca; posteriormente, foram moídas separadamente em moinho tipo Willey equipado com peneira de $1 \mathrm{~mm}$.

Os dados referentes a características dendrométricas, produção de matéria seca de serapilheira, atributos físicos e teores de matéria orgânica do solo foram submetidos à análise de variância. Posteriormente, realizou-se o desdobramento dos graus de liberdade de tratamentos e, por meio de teste de médias, avaliou-se o efeito do tráfego do forwarder no incremento médio anual e produção de matéria seca de serapilheira adotando-se o nível de significância de até $10 \%$. Para avaliar o efeito do manejo do resíduo da colheita ao final da rotação anterior, foram estabelecidos os seguintes contrastes: C1: Solo Sem Resíduo (SR) vs Solo com Resíduo de Colheita Sem Casca (SC) e Solo com Resíduo de Colheita com Casca (CC) na mesma quantidade de passadas do forwarder e profundidade; e C2: Solo com Resíduo de Colheita Sem Casca (SC) vs Solo com Resíduo de Colheita com Casca (CC) na mesma quantidade de passadas do forwarder e profundidade), adotando-se o nível de significância de até $10 \%$. Da mesma forma, para avaliar o efeito do tráfego do forwarder nos atributos físicos e teores de matéria orgânica do solo, foram estabelecidos os seguintes contrastes: (C3: sem passadas vs com passadas, no mesmo tipo de resíduo e profundidade (duas e oito); e C4: duas passadas us oito passadas, no mesmo tipo de resíduo e profundidade), adotando-se o nível de significância de até $10 \%$.

Utilizou-se para o processamento dos dados o software Statistica versão 8.0 (StatSoft, 2007).

\section{RESULTADOS E DISCUSSÃO}

\section{Produtividade florestal e serapilheira}

O incremento médio anual (IMA) representa a produtividade da floresta. OIMA médio dos tratamentos em SJE aos 2,61 anos foi de 27,2 $\mathrm{m}^{3} \mathrm{ha}^{-1} \mathrm{ano}^{-1} \mathrm{e}$ aos 5,61 anos de $42,7 \mathrm{~m}^{3} \mathrm{ha}^{-1} \mathrm{ano}^{-1}$. Em BO, o IMA médio aos 2,88 anos foi de $32,3 \mathrm{~m}^{3} \mathrm{ha}^{-1}$ ano $^{-1} \mathrm{e}$ aos 5,88 anos de $33,6 \mathrm{~m}^{3} \mathrm{ha}^{-1}$ ano $^{-1}$.

Em SJE e BO, não houve efeito do número de passadas do forwarder no IMA nas duas idades estudadas (Figuras 1a e 1b) para a mesma disposição de resíduo $(p>0,20)$. Porém, já na medição realizada em idade precoce em SJE, houve diferença no IMA do tratamento sem resíduo da colheita (SR) e dos tratamentos com resíduo, mesmo com duas passadas do forwarder $(p<0,10)$, permanecendo a diferença aos 5,61 anos (Figura 1a, contraste 1 - C1); sendo $41 \%$ maior nos tratamentos com resíduo com duas passadas e $33 \%$ maior nos tratamentos com resíduo com oito passadas, considerando a última idade avaliada (Figura 1a). Embora em BO na idade mais avançada exista tendência de menor IMA no tratamento SR em relação aos tratamentos com resíduo, não se observaram diferenças $(p>0,10)$ (Figura 1b, C 1).

Em SJE, na condição oito passadas no tratamento em que houve a manutenção de resíduo de colheita com casca (CC), o IMA foi $23 \%$ superior que aquele do tratamento com manutenção de resíduos da colheita sem casca (SC), em ambas as idades (Figura 1a, C 2). No entanto, diferenças não foram observadas com duas passadas ao se comparar os tratamentos $\mathrm{CC}$ e SC nas duas idades avaliadas $(p>0,10)$ (Figura 1a, C 2). Em BO, o IMA não diferiu entre os tratamentos CC e SC ( $p>0,10)$ em ambas as idades avaliadas, independentemente do número de passadas do forwarder (Figura 1b, C 2).

Incrementos médios anuais significativamente menores em razão do tráfego foram observados já nos primeiros dois anos e se mantiveram até a idade de colheita, com respostas de maior magnitude no solo oxídico de SJE do que no solo caulinítico de BO. Seixas e Souza (2007), avaliando o efeito da compactação do solo por causa do tráfego de trator mais carreta (massa total de $8 \mathrm{Mg}$ ) em solo arenoso, não observaram diferença $(p>0,05)$ entre os tratamentos com até 20 passadas na produtividade ao final de uma rotação de sete anos de $E$. grandis. Contudo, observou-se menor valor numérico a partir de cinco passadas.

Dedecek e Gava (2005) observaram redução de produtividade do eucalipto de até $66 \%$ aos sete anos em rebrota nas linhas com tráfego (caminhão toco). Silva et al. (2006) verificaram que a produção de matéria seca de raízes, matéria seca total e densidade de raízes de mudas de eucalipto foi reduzida pela compactação do solo na condição de maior umidade $\left(0,20 \mathrm{~kg} \mathrm{~kg}^{-1}\right)$ em Latossolo Vermelho-Amarelo, atingindo 40, 30 e $39 \%$ de redução, respectivamente. Porém, em baixos valores de umidade não houve efeito da compactação na produção do eucalipto, sendo a umidade do solo por ocasião do tráfego fator importante para que a compactação do solo converta em perda de produtividade, uma vez que essa facilita o ajuste de partículas e reduz a resistência dos agregados à deformação física (Silva et al., 2006). Os mesmos autores não observaram efeitos da compactação na produção de matéria seca total e de raízes de mudas em Latossolo Amarelo, mesmo solo deste estudo. Ressalta-se que, por ocasião da aplicação dos tratamentos (passadas do forwarder), a umidade média do solo em SJE era de $0,36 \mathrm{~kg} \mathrm{~kg}^{-1}$; e de $0,26 \mathrm{~kg} \mathrm{~kg}^{-1}$, em BO, o que pode ter acentuado as respostas aos tratamentos na região de SJE.

Apesar da maior produtividade (IMA) obtida nos tratamentos com maior quantidade de resíduos deixada na área por ocasião da aplicação dos tratamentos (SC e CC), observou-se maior acúmulo 
(a)

São João Evangelista - LV

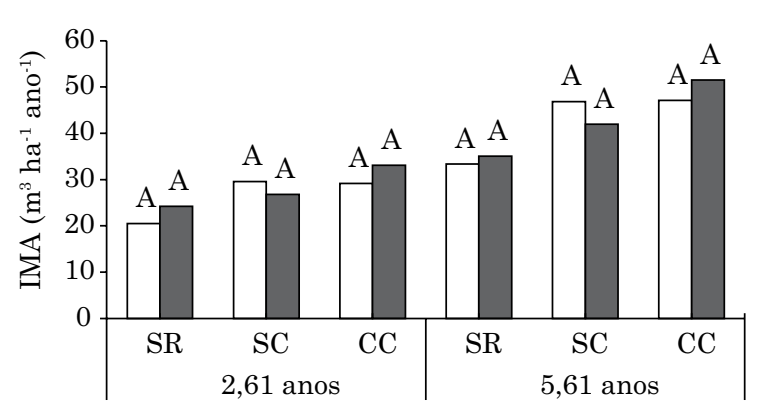

C1 2 passadas $={ }^{*} \mathrm{C} 18$ passadas $={ }^{\circ}$

C1 2 passadas $=* *$ C1 8 passadas $=* *$

$\mathrm{C} 22$ passadas $=$ ns $\mathrm{C} 28$ passadas $={ }^{\circ}$

$\mathrm{C} 22$ passadas $=$ ns $\mathrm{C} 28$ passadas $=$ * (b)

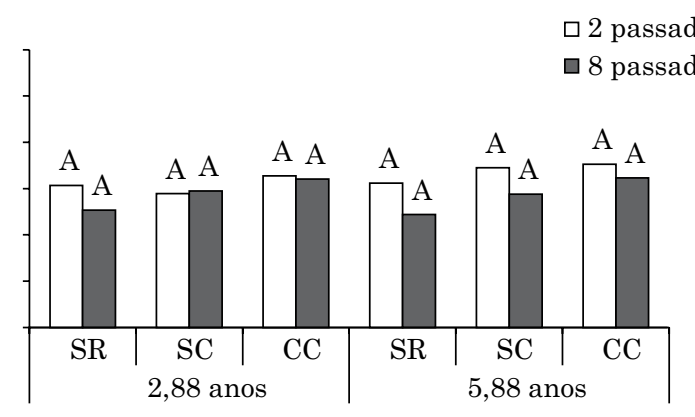

C1 2 passadas $=$ ns $\mathrm{C} 18$ passadas $=n s$ C1 2 passadas $=$ ns $\mathrm{C} 18$ passadas $=$ ns $\mathrm{C} 22$ passadas $=$ ns $\mathrm{C} 28$ passadas $=\mathrm{ns}$ $\mathrm{C} 22$ passadas $=\mathrm{ns}$ C2 8 passadas $=\mathrm{ns}$

Figura 1. Incremento médio anual (IMA) em duas idades após duas ou oito passadas do forwarder sobre resíduo da colheita do eucalipto sem casca (SC); resíduo com casca (CC); e solo sem resíduo (SR) de um Latossolo Vermelho em São João Evangelista, MG (a); e de um Latossolo Amarelo na região de Belo Oriente, MG (b). C1: Sem resíduo (SR) vs com resíduo (SC e CC); C2: resíduo sem casca (SC) vs resíduo com casca (CC). **, *, ${ }^{\circ}$ e ns: significativo a $1,5,10 \%$ e não significativo até $10 \%$, respectivamente, pelo teste F. Médias com a mesma letra maiúscula não diferem entre si quanto ao número de passadas do forwarder sobre a mesma disposição de resíduo e idade, pelo teste $F(p<0,10)$.

de serapilheira ao final da rotação no tratamento SR em SJE, tendência também notada em BO. Ao final da rotação, a produção de matéria seca de serapilheira (média geral) foi $10,7 \mathrm{Mg} \mathrm{ha}^{-1}$ (Figuras $2 \mathrm{a}$ e $2 \mathrm{~b}$ ). No tratamento $\mathrm{CC}$, a produção de matéria seca de serapilheira foi 11,5\% menor que no SR, independentemente da região de estudo e do número de passadas.

A produção de matéria seca de serapilheira não diferiu entre o número de passadas nas duas regiões do estudo $(p>0,10)$ (Figuras $2 a$ e $2 b)$. Com relação à disposição de resíduo, apenas na região de BO e no tratamento com oito passadas, a produção de matéria seca de serapilheira do tratamento SR foi $10,3 \%$ maior $(p<0,10)$ que os tratamentos com resíduo (CC e SC), observando-se a mesma tendência com duas passadas ( $p=0,139)$ (Figura $2 b, C 1)$. Nessa mesma região, diferenças não foram observadas entre o tratamento $\mathrm{CC}$ e os tratamentos $\mathrm{SC}$ (duas ou oito passadas) (Figura 2b, C 2).

Considerando que, em média, $12 \mathrm{Mg} \mathrm{ha}^{-1}$ de casca são deixados no solo na colheita florestal (Neves, 2000) e que, neste estudo, a produção de matéria seca da serapilheira foi menor no tratamento CC, pode se sugerir que a taxa de decomposição do resíduo com casca é maior comparativamente ao resíduo sem casca. Segundo Souza (2012), a manutenção da casca acelera a decomposição dos resíduos. Uma hipótese alternativa, no entanto, é que a maior compactação e consequente redução da porosidade por causa do tráfego sobre o solo nos tratamentos SR reduziram os fluxos de água $\left(\mathrm{K}_{0}\right)$, dificultando as trocas gasosas do solo com a atmosfera. Em especial, redução na difusão de $\mathrm{O}_{2}$ é esperada. Esse ambiente menos oxidativo no solo causado pela compactação reduz a atividade microbiana (Silva et al., 2011), o que pode ter contribuído para a menor taxa de decomposição da serapilheira depositada no solo do tratamento SR neste estudo. Adicionalmente, tal padrão de resposta pode também explicar os maiores teores de COT observados nos solos onde recebeu maior número de passadas. No entanto, o $\mathrm{N}$ pode ter limitado a conversão de $\mathrm{C}$ do resíduo em MOS no tratamento com a manutenção de casca em razão da sua alta relação C/N (Demolinari, 2008; Souza, 2012), sendo o motivo pelo qual, no geral, os teores de COT do tratamento CC foram menores que SC.

\section{Atributos físicos do solo}

A condutividade hidráulica média (geral) foi de 55,2 e $33,4 \mathrm{~cm} \mathrm{~s}^{-1}$ em SJE e BO, respectivamente. A disposição de resíduo na condição com duas passadas foi capaz de atenuar o efeito deletério da colheita em SJE, uma vez que valores maiores da condutividade hidráulica foram observados nos tratamentos SC e CC (Quadro 3, C 1). O tratamento CC apresentou valores de $\mathrm{K}_{0} 97 \%$ superiores em comparação ao tratamento SC na camada de 0,10-0,20 m em SJE (Quadro 3, C 2). A condutividade hidráulica dos tratamentos amostrados na linha de tráfego foram, em média, 64,8 e $21,7 \%$ do valor obtido para os tratamentos amostrados na entrelinha de tráfego em SJE e BO (Quadro 3, C 3), respectivamente, sendo não significativo apenas na camada de 0,00-0,10 m em SJE. Porém, com exceção do tratamento CC em que a condição com duas passadas apresentou maior condutividade hidráulica em SJE, diferenças nos 
(a)

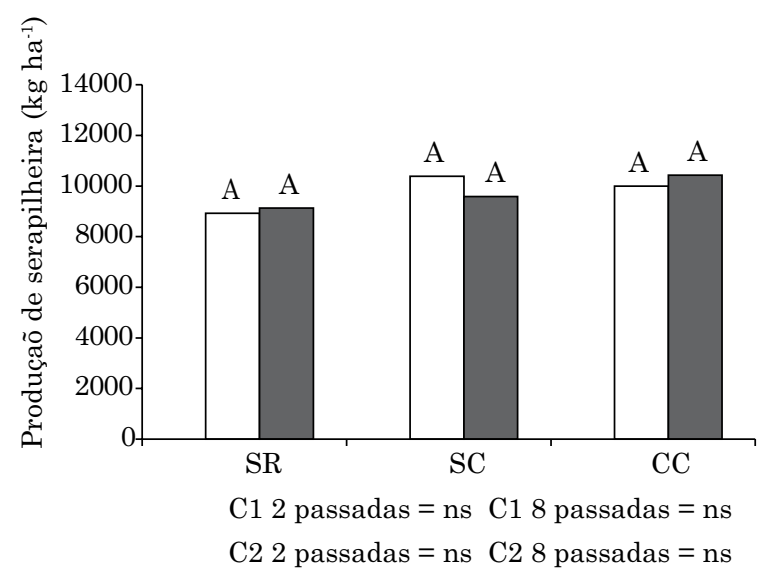

(b)

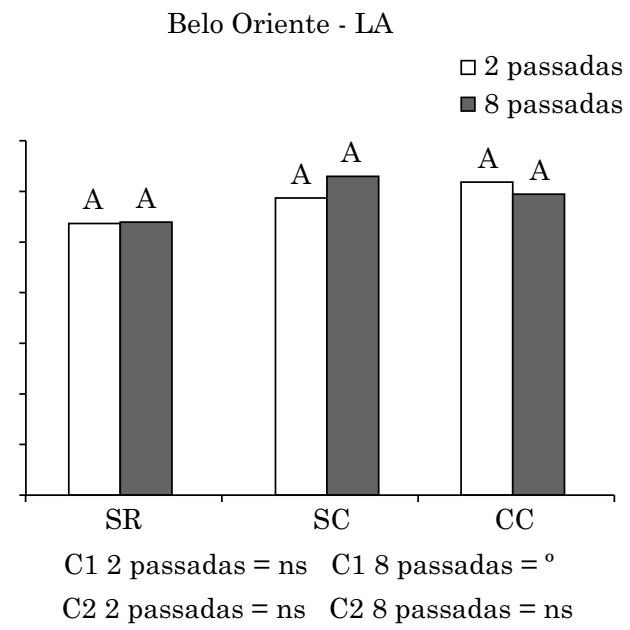

Figura 2. Produção de matéria seca de serapilheira após duas ou oito passadas do forwarder sobre resíduo da colheita do eucalipto sem casca (SC); resíduo com casca (CC); e solo sem resíduo (SR) de um Latossolo Vermelho em São João Evangelista, MG, aos 5,61 anos de idade do plantio e de um Latossolo Amarelo na região de Belo Oriente, MG, aos 5,88 anos de idade do plantio. C1: Sem resíduo (SR) vs. com resíduo (SC e CC); C2: resíduo sem casca (SC) vs. resíduo com casca (CC). ${ }^{\circ}$ e ns: significativo a $10 \%$ e não significativo até $10 \%$, respectivamente, pelo teste F. Médias com a mesma letra maiúscula não diferem entre si quanto ao número de passadas do forwarder sobre a mesma disposição de resíduo e idade, pelo teste $\mathrm{F}(\mathbf{p}<0,10)$.

tratamentos com duas e oito passadas não foram observadas (Quadro 3, C 4).

No geral, os tratamentos sem resíduo da colheita apresentaram a condutividade hidráulica reduzida para $71,5 \%$ da condutividade hidráulica quantificada nos tratamentos CC, evidenciando a importância da permanência da casca para atenuar o efeito da compactação do solo, uma vez que o tratamento SC também evidenciou baixa condutividade hidráulica.

A microporosidade média (geral) foi de $0,40 \mathrm{~m}^{3} \mathrm{~m}^{-3}$ em SJE e 0,34 $\mathrm{m}^{3} \mathrm{~m}^{-3}$ em BO. De maneira geral, essa variável foi pouco sensível ao efeito da disposição do resíduo da colheita em ambas as regiões $(p>0,10)$ (Quadro 3, C1 e C2). O valor da microporosidade das amostras coletadas na linha de tráfego foi $16,1 \%$ maior em comparação às coletadas na entrelinha de tráfego em BO e 13,5 \% em SJE (Quadro 3, C 3) $(p<0,10)$. Os tratamentos com oito passadas e CC apresentaram maiores valores de microporosidade que com duas passadas em ambas as regiões e profundidades (Quadro 3, C 4), fato também observado para a condição SR em SJE.

A macroporosidade média em SJE foi de $0,27 \mathrm{~m}^{3} \mathrm{~m}^{-3}$, enquanto em $\mathrm{BO}$ a média geral encontrada foi de $0,20 \mathrm{~m}^{3} \mathrm{~m}^{-3}$. Observou-se que, na camada de $0,10-0,20 \mathrm{~m}$ na condição com oito passadas, o tratamento SR apresentou menores valores de macroporosidade em comparação aos tratamentos CC e SC em SJE (Quadro 3, C 1). Ainda nessa mesma camada com duas passadas, o tratamento CC demonstrou maiores valores de macroporosidade (Quadro 3, C 2). De maneira geral, a linha de tráfego evidenciou valores 25 e $36 \%$ menores de macroporosidade que da entrelinha em SJE e BO, respectivamente $(p<0,10)$ (Quadro 3, C 3). Este efeito de redução foi mais evidente na condição de oito passadas em relação a duas passadas (Quadro 3, C 4).

A porosidade total média em SJE foi de $0,68 \mathrm{~m}^{3} \mathrm{~m}^{-3}$; e em $\mathrm{BO}$, de $0,54 \mathrm{~m}^{3} \mathrm{~m}^{-3}$. Com relação ao efeito do resíduo, resultados consistentes foram observados apenas na camada de $10-20 \mathrm{~cm}$ de profundidade em SJE, onde se observaram menores valores de porosidade $(p<0,10)$ nos solos dos tratamentos SR em comparação aos $\mathrm{CC}$ e SC, tanto na condição de duas quanto de oito passadas (Quadro 3, contraste 1). Nessa mesma região e camada, os solos dos tratamentos CC apresentaram maiores valores de porosidade em comparação ao SC (Quadro 3, contraste 2). Esse mesmo resultado foi encontrado apenas na condição de duas passadas em BO (Quadro 3, contraste 2). Ainda em BO, também se observou menor valor de porosidade na condição SR com oito passadas na profundidade de 10-20 cm, comparativamente aos tratamentos com resíduo (Quadro 3, contraste 1). De maneira geral, a porosidade total foi 4,6 \% e 8,2 \% menor na condição com passadas que sem passadas, respectivamente em SJE e BO (Quadro 3, contraste 3). Porém, na camada de $0-10 \mathrm{~cm}$, não se observaram diferenças no tratamento CC ao se comparar condição de passadas e sem passadas. Valores menores foram verificados na condição de oito passadas em BO, com exceção do tratamento SC (Quadro 3, contraste 4); e em SJE, apenas no tratamento $\mathrm{CC}$. 


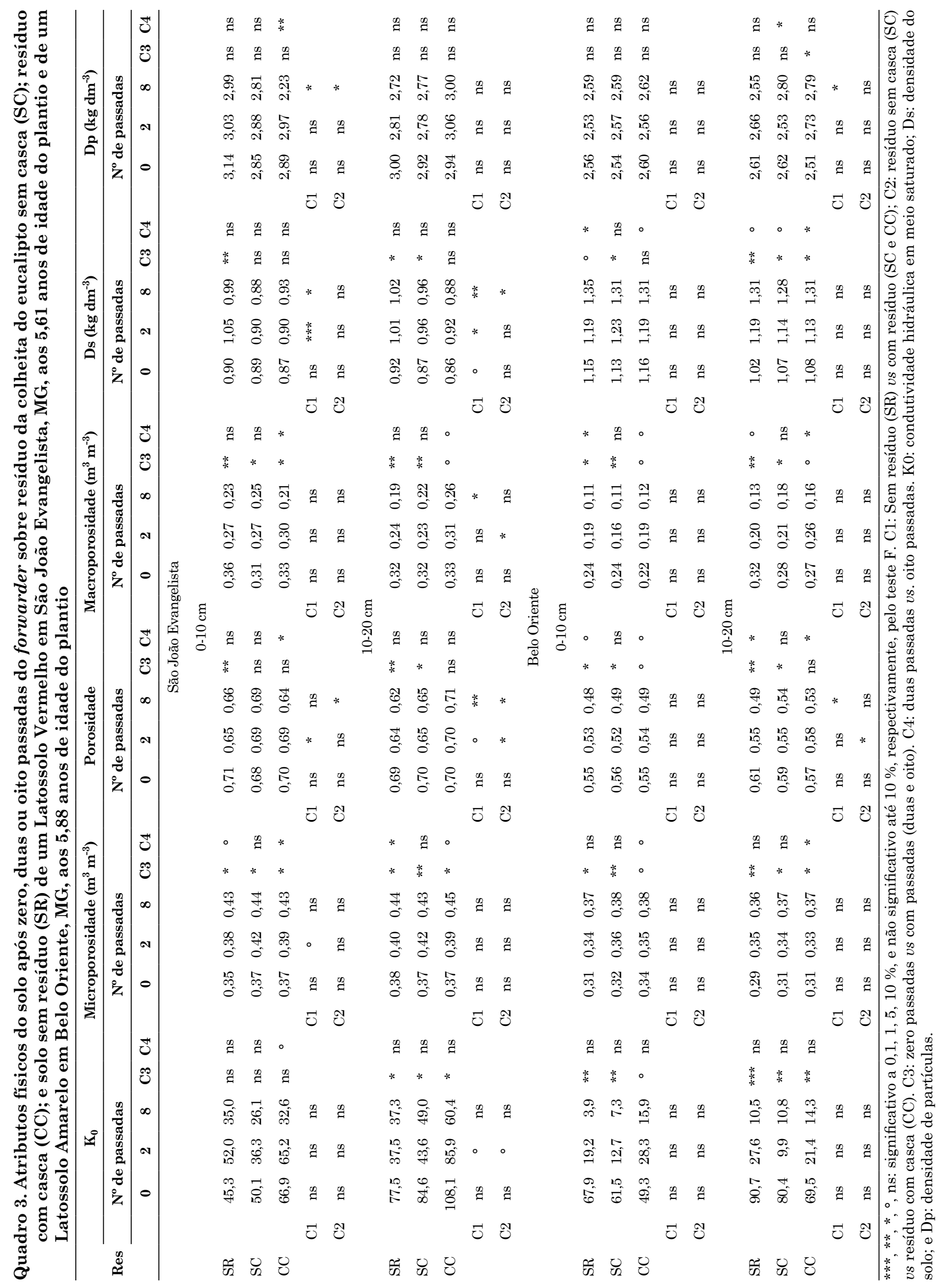


A densidade do solo (Ds) média (geral) foi de $0,93 \mathrm{Mg} \mathrm{m}^{-3}$ em SJE; e de $1,20 \mathrm{Mg} \mathrm{m}^{-3}$, em BO. Em SJE, os solos dos tratamentos SR apresentaram maiores Ds que os dos tratamentos com resíduo (Quadro 3, contraste 1). Porém, na camada de 10-20 cm, o tratamento CC evidenciou menor Ds que o tratamento SC na condição de oito passadas. Em BO, não se observaram diferenças para o efeito da disposição do resíduo na Ds (Quadro 3, contrastes 1 e 2). Em SJE, notaram-se maiores valores de Ds na camada de 10-20 cm nos tratamentos com passadas em comparação aos tratamentos sem passadas, exceção para o tratamento CC; na camada de $0-10 \mathrm{~cm}$, a Ds foi maior apenas na condição com passadas no tratamento SR (Quadro 3, contraste 3). Em BO, os tratamentos sem passadas demonstraram menores valores de Ds independentemente da disposição de resíduo, exceção apenas para o tratamento CC na camada de $0-10 \mathrm{~cm}$, onde não se observou diferença (Quadro 3, contraste 3). Nessa mesma região, a Ds foi maior na condição de oito passadas em comparação a duas passadas independentemente do tipo de resíduo disposto (Quadro 3, contraste 4). Em SJE não se observou diferença (Quadro 3, contraste 4).

Os incrementos de Ds encontrados neste estudo ao se considerar a média de passadas em relação à condição sem passadas foram de 15,6 e 12,1\% em BO e SJE, respectivamente. Os valores de Ds considerados prejudiciais estão em torno de 15 a $20 \%$ maiores que o valor inicial da densidade média do solo (Seixas, 2000).

Fernandes et al. (1997), estudando o efeito do número de passadas de um forwarder, observaram que houve diferença na densidade após a primeira passada, evidenciando diferença somente após a nona. Cerca de $80 \%$ do incremento da compactação de um solo ocorreu após as cinco primeiras passadas de um forwarder (Seixas e Souza, 2007), mas o incremento da Ds não ultrapassou $7 \%$ do valor inicial em um solo arenoso.

Em condições de casa de vegetação, plantas de $E$. grandis tiveram o crescimento de raízes inibido quando a densidade do solo apresentou valores na faixa de 1,25 a $1,35 \mathrm{Mg} \mathrm{m}^{-3}$ (Borges et al., 1986), valores esses próximos aos obtidos no LA de BO. Porém, no LV de SJE os valores encontrados foram de 0,84 a $1,05 \mathrm{Mg} \mathrm{m}^{-3}$. Tais dados sugerem que os efeitos danosos do tráfego pesado não se restringem apenas à compactação do solo, e que solos distintos apresentarão valores "críticos" diferentes de densidade solo.

Labelle e Jaeger (2011) observaram incrementos médios de 19 \% na Ds após cinco anos do tráfego do forwarder, corroborando os dados deste estudo em que os efeitos negativos iniciais do tráfego perduraram até o final da rotação seguinte. Esse padrão é preocupante, pois a baixa capacidade do solo em recuperar do evento de compactação sugere que os efeitos negativos podem ser acumulativos ao longo das rotações, podendo comprometer a sustentabilidade da produtividade à medida que rotações mais curtas sejam praticadas.

Os menores valores de Ds na linha de tráfego foram observados para os tratamentos com resíduo (contraste 1) na situação mais drástica (oito passadas) e na camada mais sensível à compactação $(10-20 \mathrm{~cm})$. De modo geral, os maiores valores de porosidade total nessa mesma camada tanto para duas quanto oito passadas evidenciam que a permanência da casca no ato da colheita do eucalipto reduz o efeito da compactação do solo, fato comprovado pelas maiores produtividades obtidas nessa situação em ambas às regiões avaliadas.

A baixa densidade dos resíduos orgânicos, associada com sua susceptibilidade à deformação e elasticidade, torna-os potencialmente capazes de atenuar as cargas aplicadas sobre o solo (Braida et al., 2006). Assim, o resíduo de colheita que permanece na área pode reduzir o efeito da compactação do solo. Essa possibilidade foi confirmada por Dao (1996), ao observar que a remoção dos resíduos vegetais da superfície do solo resultou em aumentos na densidade do solo, especialmente na camada entre 5,0 e 12,5 cm de profundidade, no sistema de cultivo convencional, e entre 0 e $5,0 \mathrm{~cm}$, no plantio direto. $\mathrm{O}$ autor também concluiu que a manutenção de grandes quantidades de resíduos vegetais na superfície do solo contribuiu para o aumento da macroporosidade na camada superficial em solos sob cultivos conservacionistas. Padrão contrário foi verificado por Gupta et al. (1987), em que os autores não observaram diferenças significativas na densidade do solo, quando submetido a tráfego, tendo diferentes quantidades de resíduos de milho na superfície. Entretanto, foi constatado que com maior quantidade de resíduo na superfície houve redução da pressão atuante no solo e redução do afundamento superficial, confirmando a hipótese de que os resíduos superficiais podem atenuar cargas aplicadas sobre o solo.

A resistência à penetração mecânica no solo (RP) diferiu entre o número de passadas e tipo de resíduo. Os solos dos tratamentos SR apresentaram maiores valores de resistência à penetração, sendo valores ainda maiores com maior número de passadas (Figuras 3 e 4). Além disso, verificou-se que a camada que mais sofreu interferência pela passagem do forwarder foi a de 10-20 cm de profundidade em ambas as regiões. A umidade do solo era maior em SJE.

$\mathrm{O}$ fato de se ter observado efeito nos atributos físicos dos solos com oito passadas, deixa claro que o maior número de passadas no ato da colheita leva à maior compactação do solo e que esses efeitos perduram até ao fim da rotação seguinte. Em termos gerais, a condutividade hidráulica na linha de tráfego foi de $43 \%$ que da obtida na entrelinha (0 passadas). Essa menor condutividade está associada ao aumento da Ds pela redução de macroporos, bem 
Resíduo com casca

(a)

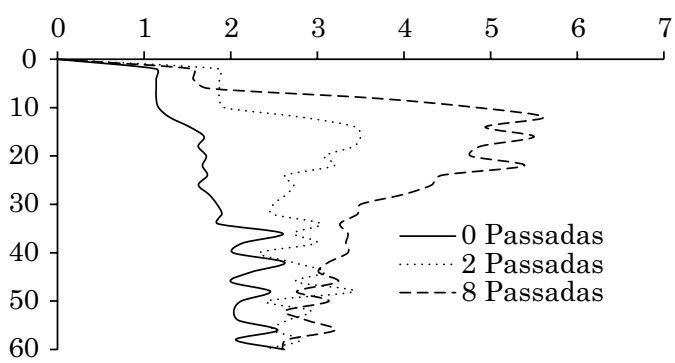

(b)

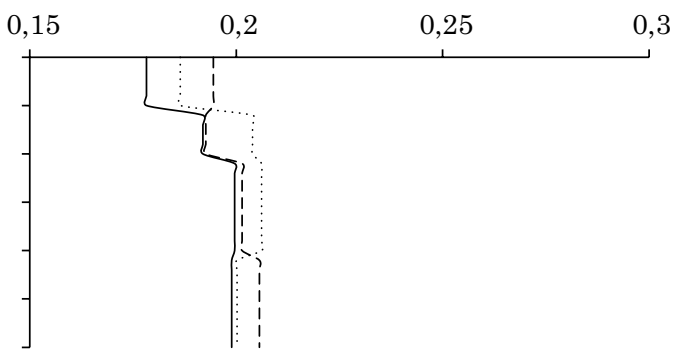

Resíduo sem casca

(c)

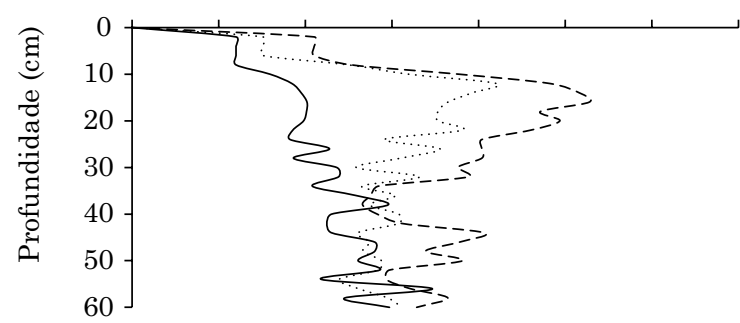

(e)

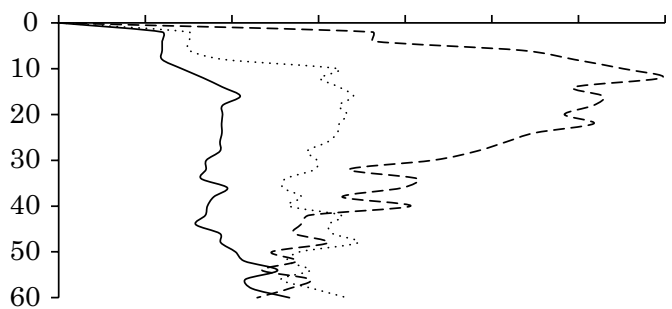

(d)

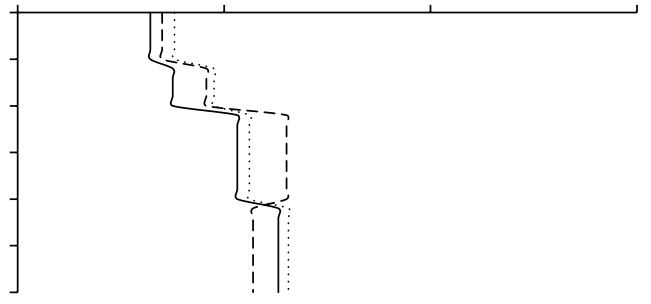

Sem resíduo

(f)

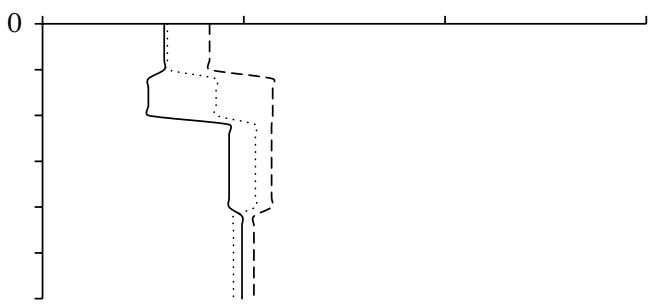

Figura 3. Resistência à penetração $(a, b, c)$ e umidade do solo (d, e, f), de acordo com o número de passadas do forwarder sobre resíduo da colheita do eucalipto sem casca (SC); resíduo com casca (CC); e solo sem resíduo (SR) de um Latossolo Vermelho em São João Evangelista, MG, aos 5,61 anos de idade do plantio.

como elevação da resistência à penetração do solo que resultará na menor atividade microbiana e, principalmente, menor desenvolvimento radicular.

Neste estudo, na condição de oito passadas, a manutenção do resíduo com casca não foi suficiente para prevenir a redução na qualidade física do solo. Portanto, pode ter havido restrição à penetração das raízes de eucalipto, uma vez que valores de resistência à penetração acima de 3,0 $\mathrm{MPa}$ foram observados. Diversos autores (Greacen e Sands, 1980; Sands et al., 1979; Seixas e Souza, 2007) relataram que valores de resistência à penetração entre 2,5 e $3,0 \mathrm{MPa}$ são suficientes para limitar o crescimento radicular.
Os atributos físicos e mecânicos do solo na camada de $10-20 \mathrm{~cm}$ foram mais influenciados pelos tratamentos que aquela de 0-10 cm. Esse efeito pode ser explicado pelos maiores teores de MOS na camada mais superficial, uma vez que a MOS aumenta a resistência do solo à compactação por aumentar a força de união entre as partículas e os agregados, elevando assim a elasticidade do solo (Braida et al., 2008). De acordo com o efeito negativo da compactação avaliado neste trabalho, fica claro a importância de um monitoramento dos atributos físicos do solo, como Ds, RP e PT, variáveis promissoras. 
(a)

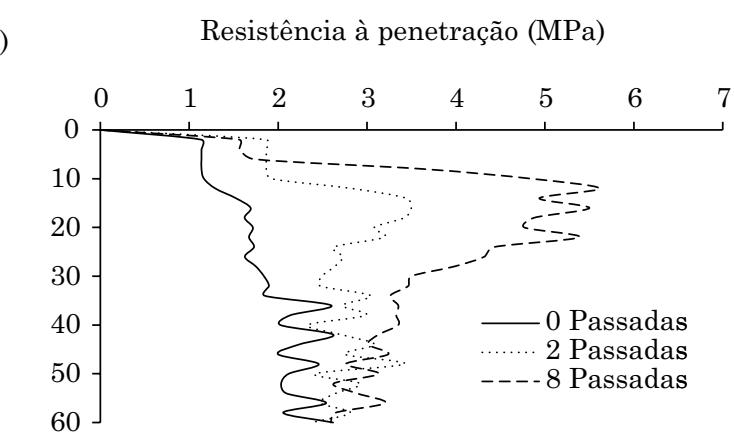

Resíduo com casca

(b)
Umidade ( $\left.\mathrm{kg} \mathrm{kg}^{-1}\right)$

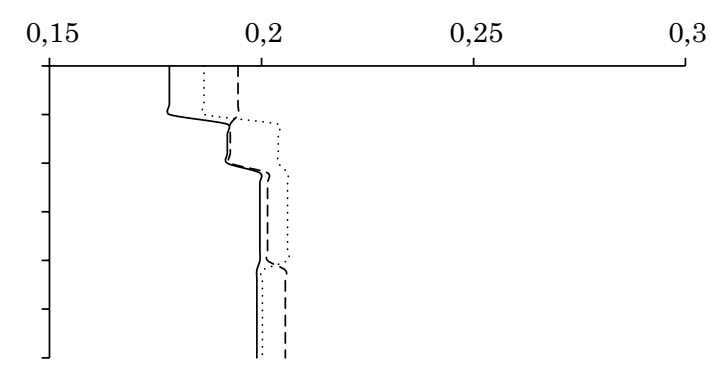

Resíduo sem casca

(c)

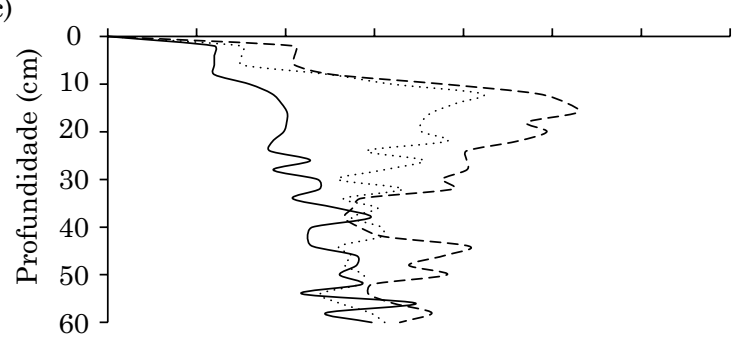

(d)

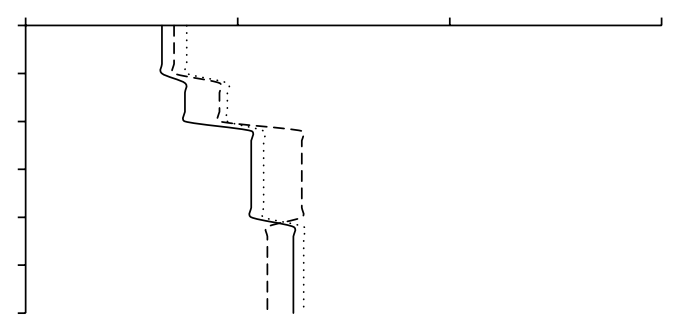

Sem resíduo

(e)

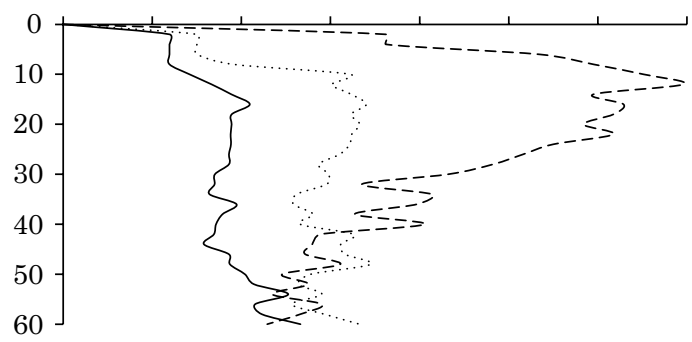

(f)

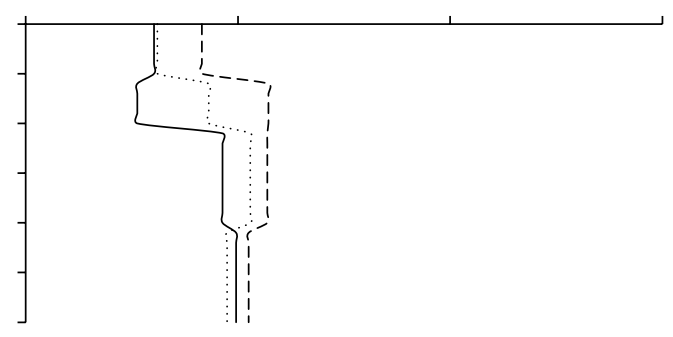

Figura 4. Resistência à penetração $(\mathrm{a}, \mathrm{b}, \mathrm{c})$ e umidade do solo $(\mathrm{d}, \mathrm{e}, \mathrm{f})$, de acordo com o número de passadas do forwarder sobre resíduo da colheita do eucalipto sem casca (SC); resíduo com casca (CC); e solo sem resíduo (SR) de um Latossolo Amarelo em Belo Oriente, MG, aos 5,88 anos de idade do plantio.

\section{Frações da matéria orgânica do solo}

Os teores médios de carbono orgânico total (COT) na profundidade de $0-20 \mathrm{~cm}$ foram de $43,7 \mathrm{~g} \mathrm{~kg}^{-1} \mathrm{em}$ SJE e 20,7 $\mathrm{g} \mathrm{kg}^{-1}$ em BO. Considerando a disposição de resíduos, para a região de SJE observou-se que os teores de COT dos tratamentos sem resíduo (SR) foram menores que os dos tratamentos com resíduo apenas na profundidade de $10-20 \mathrm{~cm}$ e na condição de maior número de passadas (Quadro 4, contraste 1). O mesmo foi observado em BO apenas no tratamento com oito passadas na camada de 0-10 cm (Quadro 4, contraste 1). Não houve diferenças no COT $(p>0,10)$ em ambas as regiões ao se comparar o tratamento de disposição de resíduo sem casca com o tratamento de resíduo com casca (Quadro 4, contraste 2). Em média, os solos dos tratamentos com oito passadas apresentaram valores de COT 12,1 e 19,1\% superiores que naqueles com duas passadas, em SJE e BO, respectivamente, sendo esse resultado mais consistente na camada de $0-10 \mathrm{~cm}$ de profundidade (Quadro 4, contraste 4). No entanto, não se observaram diferenças entre tratamentos sem passadas comparativamente aos com passadas (Quadro 4, contraste 3).

Os teores médios de C lábil (CL) na profundidade de $0-20 \mathrm{~cm}$ foram de $2,77 \mathrm{~g} \mathrm{~kg}^{-1}$ em SJE e de $2,60 \mathrm{~g} \mathrm{~kg}^{-1}$ em BO. Na condição de oito passadas, observou-se que os tratamentos com resíduo (CC e SC) apresentaram maiores teores de CL comparativamente ao tratamento SR em ambas as regiões (Quadro 4, contraste 1), fato também notado na condição de duas passadas em SJE. Tanto na camada de $0-10 \mathrm{~cm}$ quanto naquela de $10-20 \mathrm{~cm}$ (em ambas as localidades) os teores de CL do solo não evidenciaram padrão de resposta consistente em relação ao efeito dos resíduos com casca (Quadro 4, contraste 2). Com exceção dos tratamentos SC $(0-10 \mathrm{~cm})$ e CC $(10-20 \mathrm{~cm})$ em SJE, diferenças não foram observadas nos 


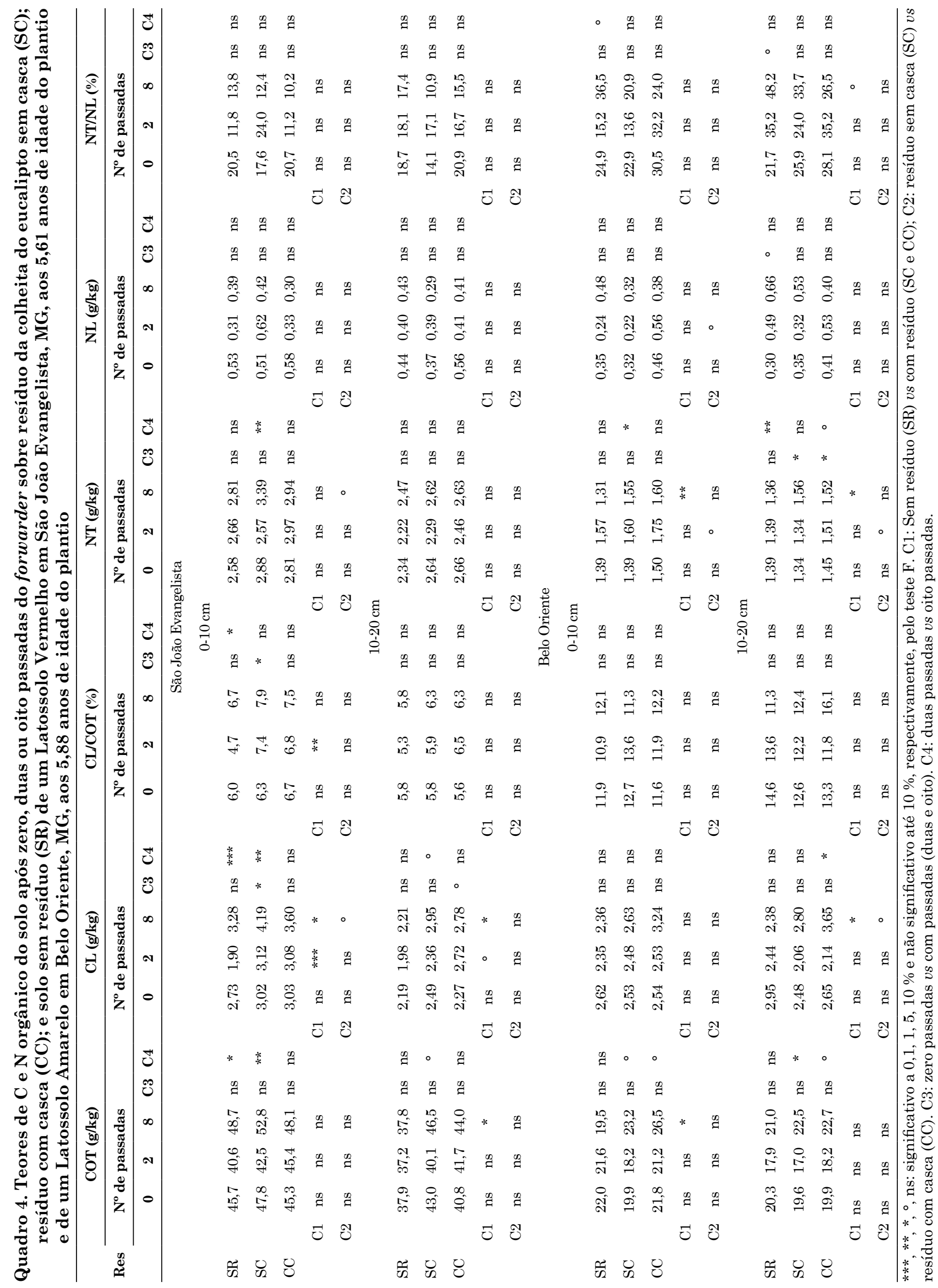


tratamentos sem passadas em relação aos com passadas (Quadro 4, contraste 3), e não se observou consistência ao se comparar duas e oito passadas para CL (Quadro 4, contraste 4).

De maneira geral, a manutenção de resíduo apresentou tendência de aumento dos teores de CL e COT, evidenciando que a maior entrada de $\mathrm{C}$ no sistema leva a maiores teores de matéria orgânica do solo nesse caso.

A contribuição relativa média do CL em relação ao COT foi de 12,5 \% em BO, o dobro em relação a SJE (6,3\%) (Quadro 4). Na região de SJE, apenas 4,8\% do COT do tratamento SR e duas passadas $(0-10 \mathrm{~cm})$ estavam na fração CL, enquanto $7 \%$ do COT estava na fração CL nos tratamentos com resíduo (Quadro 4, contraste 1). Diferenças não foram observadas entre os tratamentos CC e SC ( $>>0,10)$, independentemente de número de passadas, profundidade e local de coleta em ambas as regiões (Quadro 4, contraste 2). Apenas o tratamento SC apresentou menor contribuição relativa do CL no tratamento sem passada em relação aos com passadas na camada de $0-10 \mathrm{~cm}$ (Quadro 4, contraste 3 ).

O teor médio de $\mathrm{N}$ total (NT) foi de $2,66 \mathrm{~g} \mathrm{~kg}^{-1} \mathrm{em}$ SJE; e de $1,47 \mathrm{~g} \mathrm{~kg}^{-1}$, em BO. Na condição oito passadas, os tratamentos SC e CC apresentaram maiores teores de NT em relação ao SR em BO (Quadro 4, contraste 1). Porém, na condição de duas passadas, o tratamento CC demonstrou maior teor de NT em relação ao SC em ambas as profundidades avaliadas (Quadro 4, contraste 2). Em BO, maiores teores de NT nos tratamentos com passadas foram observados na camada de $10-20 \mathrm{~cm}$, exceção do tratamento sem resíduo (Quadro 4, contraste 3), sendo valores maiores nos tratamentos com oito passadas nas situações sem resíduo e resíduo com casca (Quadro 4, contraste 4).

Em relação ao teor de NL e da relação de NL e NT, de modo geral, não se observaram diferenças para passadas e tipo de resíduo em ambas as regiões (Quadro 4).

A maior labilidade da matéria orgânica observada em BO (maior relação CL/COT) pode ser explicada pelo menor teor de COT, que é menos da metade do COT do solo de SJE. Do mesmo modo, o teor médio de $\mathrm{N}$ total (NT) em BO representa pouco mais da metade do NT de SJE. Uma das possíveis razões para essa resposta seria a rápida decomposição de compostos carbonados mais lábeis, pois as taxas de decomposição da MOS nessa região mais baixa e mais quente (BO) são praticamente o dobro das observadas na região mais alta e de clima mais ameno (SJE) (Lima et al., 2006).

\section{CONCLUSÕES}

A redução de produtividade dos plantios pela compactação do solo promovida pelas passadas do forwarder é atenuada com a permanência dos resíduos da colheita, especialmente com a manutenção da casca das árvores na área.

A remoção de resíduo, particularmente quando há remoção da casca, leva à redução do $\mathrm{C}$ orgânico total e de frações mais lábeis de $\mathrm{C}$ e $\mathrm{N}$ do solo ao final da rotação seguinte.

O tráfego do forwarder na colheita do eucalipto da rotação anterior sobre solo sem resíduos promove redução na qualidade física do solo, com aumento da densidade e resistência à penetração e redução na porosidade e condutividade hidráulica. Esses efeitos negativos perduram até o final da rotação seguinte.

\section{AGRADECIMENTOS}

À Celulose Nipo-Brasileira S.A. (Cenibra), pela disponibilidade das áreas para o experimento e pelo apoio na coleta dos dados. À Fapemig e ao CNPq, pelo contínuo suporte financeiro às pesquisas em nossos laboratórios.

\section{REFERÊNCIAS}

Alakukku L, Elomen P. Long-term effects of a single compaction by heavy field traffic on yield and nitrogen uptake of annual crops. Soil Till Res. 1994;36:141-52.

Alvarez V VH, Novais RF, Dias LE, Oliveira JA. Determinação e uso do fósforo remanescente. Bol Inf Soc Bras Ci Solo. 2000;25:27-34.

Associations of Official Analytical Chemists - AOAC. Official methods of analysis of the Associations of Official Analytical Chemists. $12^{\text {nd }}$.ed. Washington: 1975.

Blair GJ, Lefroy RDB, Lisle L. Soil carbon fractions based on their degree of oxidation, and the development of a carbon management index for agricultural systems. Aust J Agric Res. 1995;46:1459-66.

Borges EN. Resposta da soja e do eucalipto às camadas compactadas de solo [dissertação]. Viçosa, MG, Universidade Federal de Viçosa; 1986.

Braga JL, Defelipo BV. Determinação espectrofotométrica de fósforo em extratos de solos e plantas. R Ceres. 1974;21:73-85.

Braida JA, Reichert JM, Reinert DJ, Sequinatto L. Elasticidade do solo em função da umidade e do teor de carbono orgânico. $\mathrm{R}$ Bras Ci Solo. 2008;32:477-85.

Braida JA, Reichert JM, Veiga M, Reinert DJ. Resíduos vegetais na superfície e carbono orgânico do solo e suas relações com a densidade máxima obtida no ensaio Proctor. R Bras Ci Solo. 2006;30:605-14.

Bremner JM, Mulvaney CS. Nitrogen - Total. In: Page AL, Miller RH, Keeney DR, editors. Methods of soil analysis. $2^{\text {nd }}$.ed. Madison, American Society of Agronomy/Soil Science Society of America; 1982. Pt 2. p.595-624. 
Canillas EC, Salokhe VM. A decision support system for compaction assessment in agricultural soils. Soil Till Res. 2002;65:221-30.

Cavichiolo SBV, Dedecek RA, Gava JL. Modificações nos atributos físicos de solos submetidos a dois sistemas de preparo em rebrota de Eucalyptus saligna. R Árvore. 2005;29:571-7.

Dao TH. Tillage system and crop residue effects on surface compaction of a Paleustoll. Agron J. 1996;88:141-8.

Dedecek RA, Gava JL. Influência da compactação do solo na produtividade da rebrota de eucalipto. R Árvore. 2005;29:383-90.

Defelipo BV, Ribeiro AC. Análise química do solo; metodologia. Viçosa, MG: Universidade Federal de Viçosa; 1997. (Boletim de Extensão, 29).

Demolinari MSM. Transferência do carbono de resíduos da colheita de eucalipto para as frações da matéria orgânica do solo [dissertação]. Viçosa, MG: Universidade Federal de Viçosa; 2008.

Dias Júnior MS. Avaliação quantitativa da sustentabilidade estrutural de um Latossolo Vermelho-Amarelo situado em áreas experimentais da Cenibra: relatório do projeto de pesquisa. Lavras: Universidade Federal de Lavras; 1999.

Empresa Brasileira de Pesquisa Agropecuária - Embrapa. Centro Nacional de Pesquisa de Solos. Manual de métodos de análise de solo. $2^{\text {a }}$.ed. Rio de Janeiro: 1997.

Empresa Brasileira De Pesquisa Agropecuária - Embrapa. Centro Nacional de Pesquisa de Solos. Sistema brasileiro de classificação de solos. $3^{\text {a }}$.ed. Brasília, DF: 2013

Fenner PT. Compactação do solo. In: Machado CC, editor. Colheita florestal. Viçosa, MG: Universidade Federal de Viçosa; 2002. p.375-96

Fernandes HC, Orlando RC, Lanças KP. Compactação do solo em relação à exploração florestal: influência do "forwarder" e do "harvester". Eng Agric. 1997;5:276-80.

Ferreira PA. Drenagem de terras agrícolas. Viçosa, MG: Universidade Federal de Viçosa; 1999.

Greacen EL, Sands R. Compaction of forest soils. A review. Aust J Agric Res. 1980;18:163-89.

Gupta SC, Schneider EC, Larson WE, Hadas A. Influence of corn residue on compression and compaction behavior of soils. Soil Sci Soc Am J. 1987;51:207-12.

Labelle ER, Jaeger D. Soil compaction caused by cut-to-length forest operations and possible short-term natural rehabilitation of soil density. Soil Sci Soc Am J. 2011;75:2314-29.

Lima AMN, Silva IR, Neves JCL, Novais RF, Barros NF, Mendonça ES, Smyth TJ, Moreira MS, Leite FP. Soil organic carbon dynamics following afforestation of degraded pastures with eucalyptus in Southeastern Brazil. For Ecol Manage. 2006;235:219-31.

Lopes ES, Sampietro JA, Pereira ALN, Oliveira D. Compactação de um Latossolo submetido ao tráfego de skidder com diferentes rodados. Floresta. 2011;41:471-80.

Lopes SE, Fernandes HC, Vieira LB, Machado CC, Rinaldi PCN. Compactação de um solo de uso florestal submetido ao tráfego de arraste de madeira. R Árvore. 2006;30:369-76.

Marchão RL, Balbino LC, Silva EM, Santos Junior JDG, As MAC, Vilela L, Becquer T. Qualidade física de um Latossolo Vermelho sob sistemas de integração lavoura-pecuária no Cerrado. Pesq Agropec Bras. 2007;6:873-82

Neves JCL. Produção e partição de biomassa, aspectos nutricionais e hídricos em plantios clonais de eucalipto na região litorânea do Espírito Santo [tese]. Campos dos Goytacazes: Universidade Estadual do Norte Fluminense; 2000.

Reichert JM, Suzuki LEAS, Reinert DJ. Compactação do solo em sistemas agropecuários e florestais: identificação, efeitos, limites críticos e mitigação. Tópicos Ci Solo. 2007;5:49-134.

Reichert JM, Suzuki LEAS, Reinert DJ, Horn R, Hakansson I. Reference bulk density and critical degree-of-compactness for no-till crop production in subtropical highly weathered soils. Soil Till Res. 2009;2:242-54.

Ruiz HA. Incremento da exatidão da análise granulométrica do solo por meio da coleta da suspensão (silte + argila). R Bras Ci Solo. 2005;29:297-300

Sahrawat KL. Nitrification in some tropical soils. Plant Soil. 1982;65:81-286.

Sands R, Greacen EL, Gerard GJ. Compaction of sandy soils in radiata pine forests. I. A penetrometer study. Aust J Agric Res. $1979 ; 17: 101-13$

Seixas F, Souza CR. Avaliação e efeito da compactação do solo, devido à frequência de tráfego, na produção de madeira de eucalipto. R Árvore. 2007;31:1047-52.

Seixas F. Compactação do solo devido à colheita de madeira [tese]. Piracicaba: Escola Superior de Agricultura "Luiz de Queiroz", Universidade de São Paulo; 2000.

Shang C, Tiessen H. Organic matter lability in a tropical Oxisol: evidence from shifting cultivation, chemical oxidation, particle size, density, and magnetic fractionations. Soil Sci. 1997;162:795-807.

Silva AR, Dias Junior MS, Leite FP. Propriedades físicas e mecânicas de Latossolos em diferentes manejos florestais. Ci Agrotecnol. 2010;34:1483-91.

Silva SR, Barros NF, Vilas Boas JEB. Crescimento e nutrição de eucalipto em resposta à compactação de Latossolos com diferentes umidades. R Bras Ci Solo. 2006;30:759-68.

Silva SR, Barros NF, Costa LM, Mendonça ES, Leite FP. Alterações do solo influenciadas pelo tráfego e carga de um forwarder nas entrelinhas de uma floresta de eucalipto. $\mathrm{R}$ Bras Ci Solo. 2007;31:371-7.

Silva SR, Silva IR, Barros NF, Mendonça ES. Effect of compaction on microbial activity and carbon and nitrogen transformations in two Oxisols with different mineralogy. $\mathrm{R}$ Bras Ci Solo. 2011;35:1141-9.

Souza IF. Decomposição de resíduos da colheita e transferência de carbono para o solo em plantações de eucalipto [dissertação]. Viçosa, MG: Universidade Federal de Viçosa; 2012.

Statsoft Inc. Statistica (Data Analysis Software System), version 8.0; 2007. Available at: www.statsoft.com.

Stolf R, Fernandes J, Furlani Neto VL. Recomendação para uso do penetrômetro de impacto modelo IAA/PLANALSUCAR/STOLF. STAB - Açúcar Álcool Subprod. 1983;3:18-23.

Yeomans JC, Bremner JM. A rapid and precise method for routine determination of organic carbon in soil. Commun Soil Sci Plant Anal. 1988;19:1467-76. 